\title{
Sample-size dependence of diversity indices and the determination of sufficient sample size in a high-diversity deep-sea environment
}

\author{
Karline Soetaert ${ }^{1}$, Carlo Heip ${ }^{2}$ \\ ${ }^{1}$ Marine Biology Section, Zoology Institute, State University of Gent, Belgium \\ ${ }^{2}$ Delta Institute for Hydrobiological Research, Vierstraat 28,4401 EA, Yerseke, The Netherlands
}

\begin{abstract}
Diversity indices, although designed for comparative purposes, often cannot be used as such, due to their sample-size dependence. It is argued here that this dependence is more pronounced in high diversity than in low diversity assemblages and that indices more sensitive to rarer species require larger sample sizes to estimate diversity with reasonable precision than indices which put more weight on commoner species. This was tested for Hill's diversity numbers $N_{0}$ to $N_{\infty}$ (Hill 1973) and some other commonly used diversity indices for a high-diversity nematode assemblage in the Mediterranean deep sea.
\end{abstract}

Although diversity indices were introduced into the ecological literature more than $20 \mathrm{yr}$ ago and have very often been criticized since, their use in applied ecological research, mainly in pollution impact studies, is still very popular (e.g. Heip et al. 1988a).

A fundamental drawback of many diversity indices is their sample-size dependence (Sanders 1968 and references therein), making comparison between studies difficult. Yet, the main purpose of quantifying diversity by a numerical index is to provide means for comparison between different communities. One way of avoiding incomparability of measurements resulting from different-sized samples was provided by the rarefaction method of Sanders (1968). In this method, one calculates the number of species expected from each sample if sampling size is standardized. Hurlbert (1971) showed that the rarefaction method generally overestimates the expected number of species present and he introduced an exact computational formula for this index: the expected number of species in a sample with size $n_{1}$ drawn from a population of size $N$ which had $S$ species, is given by

$$
\operatorname{ES}(\mathrm{n})=\sum_{i=1}^{S} \mid 1-\left[\left(\begin{array}{c}
\mathrm{N}-\mathrm{N}_{i} \\
n
\end{array}\right) /\left(\begin{array}{l}
N_{i} \\
n
\end{array}\right)\right]
$$

where $N_{i}$ represents the number of individuals in the $i^{\text {th }}$ species in the full sample (Hurlbert 1971). This index was used by Heck et al. (1975) to estimate sufficient sample size for the calculation of the number of species in a sample.

However, a mere species count, like ES (n), does not cover all information present in the community as it is not related to the way the individuals are divided among the species. Thus other diversity measures should be considered as well.

Sample size dependence of diversity indices. Intuitively, one expects that not all diversity indices are equally influenced by sample size, and that also the type of community (with high or low diversity) plays a role.

Let us consider the influence of sample size on Hill's diversity numbers $\left(\mathrm{N}_{a}\right)$ of various orders (Hill 1973). Hill's diversity number of order a is given by:

$$
N_{a}=\left|\sum_{i=i}^{S} p_{i}^{a}\right|(1 / 1-a)
$$

where $S=$ the number of species; $p_{i}=$ the relative abundance of the $\mathrm{i}^{\text {th }}$ species.

These diversity numbers have the following advantages: (1) They have a unifying notation. (2) With increasing order they become less sensitive to the rare, more sensitive to the more abundant species. (3) They are expressed in functional or apparent numbers of species (rather than bits/individual, probabilities). (4) They are related in a mathematical way to commonly used diversity indices:

$N_{0}=S$, the number of species present in the sample;

$N_{1}=\exp \left(\mathrm{H}^{\prime}\right)$, with $\mathrm{H}^{\prime}=$ the Shannon-Wiener diversity index, calculated by naperian logarithms; 
$\mathrm{N}_{2}=1 / \theta$, with $\theta=$ Simpson's dominance index (see also Heip et al. 1988b)

We focus on 2 (hypothetical) end-types of communities. The first has the highest diversity possible: every species is represented by only one individual, or if $n=$ the number of individuals examined, each species has a relative abundance of $1 / \mathrm{n}$. A random selection of, say, 100 additional individuals yields 100 additional species.

Thus, $S=n, p_{i}=1 / n$ and $N_{a}$ becomes:

$$
\begin{aligned}
N_{\mathrm{a}} & =\left|\sum_{i=1}^{5}(1 / \mathrm{n})^{\mathrm{a}}\right|(1 / 1-\mathrm{a}) \\
& =\ln \mathrm{n}^{-\mathrm{a}} \mid(1 / 1-\mathrm{a}) \\
& =\mathrm{n}
\end{aligned}
$$

All Hill's diversity numbers are equally large: $N_{0}=$ $N_{1}=N_{2}=\ldots=N_{\infty}=$ the number of individuals examined (Hill 1973). They are maximally dependent on sample size.

At the other extreme, the second community consists of only one species, i.e. the least diverse possible. A random selection of 100 individuals will yield no additional species and Hill's diversity numbers are: (with $\mathrm{S}=1, \mathrm{p}_{1}=1$ )

$$
\begin{aligned}
N_{a} & =\left(1^{a}\right)^{(1 / 1-a)} \\
& =1
\end{aligned}
$$

Thus, in the least diverse case, Hill's diversity numbers are not dependent on sample size.

In reality, community structure will be somewhere between these 2 end-type communities. Here, we expect that the impact of the most common species can be assessed at relatively low sample sizes, while with increasing sampling effort more and more rare species will be encountered. Thus, a fair estimate of Hill's diversity numbers of higher order (emphasizing common species) should be reached at low sampling sizes, whereas assessing Hill's diversity numbers of low order (emphasizing rare species) requires a larger sample size.

A case study. The sensitivity of Hill's diversity indices to sample size was examined for a diverse nematode assemblage in the Mediterranean $(990 \mathrm{~m}$ depth). The station is part of a transect described in Soetaert \& Heip (1989), where details on methodology can be found. All 808 nematodes found in 2 pooled samples of $10 \mathrm{~cm}^{2}$ from a box corer were identified to species level. Ten random selections of 100,150 , ., 700 and 750 individuals were then drawn from this pool (consisting of 808 examined individuals) and Hill's diversity indices of order $0,1,2$ and $\infty$ were calculated from all selections. Next, for every index, the significance of changes due to sample size was investigated by means of a Kruskal-Wallis test.

The rarefaction curves are represented in Fig. 1.

The Kruskal-Wallis test was significant for the indices $N_{0}, N_{1}$ and $N_{2}(p<0.005)$. The values of $N_{0}, N_{1}$ and $\mathrm{N}_{2}$ increase significantly with increasing sample size ( $r=$ respectively $0.98,0.94$ and $0.86, p<0.01$ ). $N_{0}$ is most sensitive to sample size (the increase is most pronounced), while indices of higher order are successively less sensitive (i.e. their rarefaction curves are successively flatter). $N_{\infty}$, which only depends on the density of the most common species, does not change significantly with sample size. The expected number of species $E S(n)$ is also independent of the number of individuals determined.

Except for $N_{0}$ (the number of species in the sample) a

\section{Number of species}

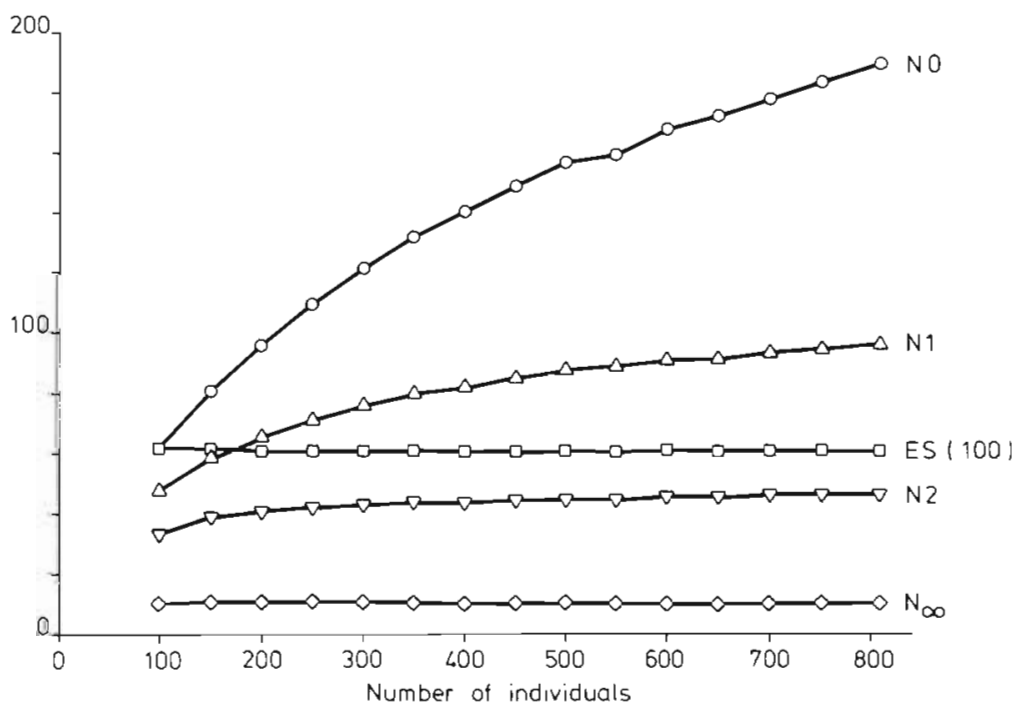

Fig. 1 Mean diversity (in number of species) for various sample sizes in a Mediterranean deep-sea nematode assemblage 
'platform' seems to be reached, indicating that the estimate of species diversity can be considered relatively precise at 808 individuals. If we take the diversity values calculated for 808 individuals as exact, then the number of organisms which should be determined to obtain an estimate with a precision of, say at least $90 \%$, is about 500 individuals for $N_{1}$ and 250 individuals for $\mathrm{N}_{2}$. The value of $\mathrm{N} \infty$ is then precisely estimated at 100 individuals or less. In order to obtain a precise estimate for the number of species present $\left(N_{0}\right)$, more than 800 individuals should be examined.

When the sample size is increased from 100 to 200 individuals, the number of species in the sample $\left(\mathrm{N}_{0}\right)$ increases by $35 \%, N_{1}$ increases by $27 \%$ and $N_{2}$ by $19 \%$ The Shannon-Wiener diversity index increases from 5.58 bits individual $^{-1}$ (100 ind.) to 6.04 bits ind. $^{-1}$ (200 ind.) and to 6.58 bits ind. $^{-1}$ (808 ind $^{-1}$ ).

As the Shannon-Wiener diversity index is related to $\mathrm{N}_{1}$ by a logarithmic function $\left(\mathrm{H}^{\prime}\right.$ in bits ind. ${ }^{-1}=\ln \left(\mathrm{N}_{1}\right)^{\prime}$ In (2)), its rarefaction curve tends to flatten down more quickly, and hence it is less sensitive to the sample size than $\mathrm{N}_{1}$. Indeed, if an error of $10 \%$ is allowed, a reasonable estimate of $\mathrm{H}^{\prime}$ is already obtained at 200 individuals (500 individuals for N1). On the other hand, this indicates that $H^{\prime}$ is less fit for distinguishing differences in high diversity assemblages than $N_{1}$. Simpson's index $\left(1 / \mathrm{N}_{2}\right)$ requires about 250 individuals to estimate with $90 \%$ precision.

If one wants to compare diversity indices from different areas with non-standardized sample sizes, either one can resort to the density-independent index (ES(n)) or, if the species-abundance data are given, the sample size can be standardized by randomization techniques (as above) and the diversity indices calculated on the reduced data set. The randomization technique can also be used to estimate the number of individuals a subsample has to contain in order to obtain reasonable' estimates of a diversity index for the entire sam-

This note was submitted to the editor ple. It should be noted that a quicker method of estimating sufficient sample size for the calculation of the number of species in a sample $\left(\mathrm{N}_{0}\right)$ is by using Hurlbert's expected number of species for $100,150, \ldots$. $N$ individuals (Heck et al. 1975) instead of random draws.

Acknowledgements. This project was funded through grant 2.9007.82 'Ecology and Systematics of Marine Organisms' (C. Heip, principal investigator) of the Belgian National Fund for Collective Fundamental Research. K.S. acknowledges a grant as 'aspirant' of the Belgian National Fund for Scientific Research. We thank W. Gyselinck for the making of slides, D. Van Gansbeke and the crew of the RV 'Dubuisson' (Station de Recherches Sous-Marines et Océanographiques, Calvi, Corsica) for their help in sampling. We thank A. Bolsius for the drawing. This is contribution no. 464 of the Delta Institute for Hydrobiological Research.

\section{LITERATURE CITED}

Heck, K. L. Jr, Van Belle, G., Simberloff, D. (1975). Explicit calculation of the rarefaction diversity measurement and the determination of sufficient sample size. Ecology 56: $1459-1461$

Heip, C., Warwick, R. M., Carr, M. R., Clarke, R., Herman, P. M. J., Huys, R., Smol, N., Van Holsbeke, K. (1988a). Analyses of community attributes: the benthic meiofauna of Langesund and Frierfjord, Norway. Mar. Ecol. Prog. Ser. 46: $171-180$

Heip, C., Herman, P. M. J., Soetaert, K. (1988b). Data processing, evaluation and analysis. In: Higgins, R. H., Thiel, H. (eds.) Introduction to the study of meiofauna. Smithsonian Institution Press, p. 197-231

Hill, M. O. (1973). Diversity and evenness: a unifying notation and its consequences. Ecology 54: $427-432$

Hurlbert, S. H. (1971). The nonconcept of species diversity: a critique and alternative parameters. Ecology 52: 577-586

Sanders, H. L. (1968). Marine benthic diversity: a comparative study. Am. Nat. 102: 243-282

Soetaert, K., Heip, C. (1989). The size structure of nematode assemblages along a Mediterranean deep-sea transect. Deep Sea Res. 36: 93-102

Manuscript first received: May 25, 1989

Revised version accepted: September 21, 1989 